\title{
Evaluation and Optimization of Influence of Permeability Property and Concentration of Polymethacrylic Polymers on Microspheres of Metformin $\mathrm{HCl}$
}

\author{
Ikramul Hasan ${ }^{1}$, Shovan Paul ${ }^{1}$, Sharmin Akhter ${ }^{2}$, Navid J ubaer Ayon ${ }^{1}$ \\ and Md. Selim Reza ${ }^{1}$ \\ ${ }^{1}$ Department of Pharmaceutical Technology, Faculty of Pharmacy, University of Dhaka \\ Dhaka-1000, Bangladesh. \\ ${ }^{2}$ Department of Pharmacy, University of Asia Pacific, Dhanmondi, Dhaka-1209, Bangladesh
}

\begin{abstract}
Metformin $\mathrm{HCl}$ microspheres were prepared with the aim of increasing its bioavailability and decreasing gastrointestinal side effects by means of sustained action. Eudragit RSPO and Eudragit RLPO, polymers of different permeability characteristics were used to prepare different microspheres. Emulsification solvent evaporation technique using acetone as the internal phase and liquid paraffin as the external phase was the method of choice. Six formulations were prepared using two polymers. The effect of drug loading and polymeric property on the surface morphology, entrapment efficiency, particle size and release characteristics of the microspheres were examined. FTIR and DSC studies established compatibility of the drug with the polymers. SEM studies clearly revealed the effect of drug loading and polymeric nature on the surface morphology of the microspheres. Entrapment efficiencies were within $77.09-97.11 \%$ and particle size of all the batches were in the acceptable range. Release data were treated with different mathematical kinetic models. The drug release profile showed that Eudragit RSPO and Eudragit RLPO have opposite effect on drug release. On the other hand, increase in drug loading results in increased drug release. Kinetic modeling of in vitro dissolution profiles revealed that the drug release mechanism varies from diffusion controlled to anomalous type.
\end{abstract}

Key words: Emulsification solvent evaporation, Metformin HCl, Microsphere, Eudragit RSPO, Eudragit RLPO.

\section{INTRODUCTION}

Microencapsulation is the application of a thin coating to individual core materials that have an arbitrary particle size range between 1 and 1000 $\mu \mathrm{m} .{ }^{1,2}$ In pharmaceutical sciences, microencapsulation is widely used to mask tastes or odors, prolong release, impart stability to drug molecules, improve bioavailability, and as multi-particulate dosage forms to produce controlled or targeted drug delivery. ${ }^{3-5}$ Thus, it is therefore a rapidly expanding technology for achieving sustained-release dosage forms.

Correspondence to: Md. Selim Reza

Tel: +880-2-8612069, Fax: +880-28615583

E-mail: selim.du@gmail.com

Dhaka Univ. J. Pharm. Sci. 12(2): 131-141, 2013 (December)
Microencapsulation can be used to retard the release of a drug in the body. This may permit one to control the release of dose to substitute several doses of non-encapsulated drug and also may decrease toxic side effects for some drugs by preventing high initial concentrations in the blood. There is usually a certain desired release pattern. In some cases, it is zero-order, i.e. the release rate is constant. In this case, the microcapsules deliver a fixed amount of drug per minute or per hour during the period of their effectiveness. This can occur as long as a solid reservoir or dissolving drug is maintained in the microcapsule.

Metformin $\mathrm{HCl}$ is an oral antidiabetic drug of the biguanide class. It is the first-line drug of choice for the treatment of type II diabetes, particularly, in 
overweight and obese people and those with normal kidney function. ${ }^{6-8}$ Its use in gestational diabetes has been limited by safety concerns. It is also used in the treatment of polycystic ovary syndrome ${ }^{9,10}$ and has been investigated for other diseases where insulin resistance may be an important factor. ${ }^{11}$ Metformin $\mathrm{HCl}$ works by suppressing glucose production by the liver.

Metformin $\mathrm{HCl}$ is a BCS class III drug and like other drugs of this group it shows lower level of absorption. The absolute bioavailability of a Metformin $\mathrm{HCl} 500 \mathrm{mg}$ tablet given under fasting conditions is approximately 50 to $60 \%$. Studies using single oral doses of Metformin $\mathrm{HCl} 500 \mathrm{mg}$ to 1500 $\mathrm{mg}$, and $850 \mathrm{mg}$ to $2550 \mathrm{mg}$, indicate that there is a lack of dose proportionality with increasing doses, which is due to decreased absorption rather than an alteration in elimination. ${ }^{12}$

Among the different approaches used for obtaining sustained-release delivery systems, microspheres' system appears as one of the most efficient systems because of less local gastric interference and most importantly limited risk of dose dumping.

Use of different types of methacrylic resins (Eudragit) for controlled drug delivery appears particularly attractive due to their high chemical stability properties. ${ }^{13}$ Eudragit RLPO and RSPO are $\mathrm{pH}$-independent polymers, inert to the digestive tract, impermeable to water, as well as capable of swelling and release active ingredients by diffusion. ${ }^{14}$ As a result microspheres of Metformin $\mathrm{HCl}$ using Eudragit RSPO or Eudragit RLPO will give a time dependent controlled release which will ultimately potentiate the pharmacologic efficacy of the drug. ${ }^{1}$

\section{MATERIALS AND METHODS}

Metformin $\mathrm{HCl}$ was collected as a gift sample from Beximco Pharmaceuticals Limited, Bangladesh. All other ingredients were procured from local market.

Preparation of Metformin $\mathrm{HCl}$ microspheres. ${ }^{16}$ Microspheres containing highly watersoluble Metformin $\mathrm{HCl}$ were prepared by non- aqueous emulsion solvent evaporation method using two different (poly-trimethylammonioethyl methacrylate) copolymers: Eudragit RLPO and RSPO, having different permeability characteristics. Weighed quantities of Eudragit RLPO or RSPO were completely dissolved in $20 \mathrm{ml}$ acetone. Weighted quantity of Metformin $\mathrm{HCl}$ was then added and stirred using a overhead stirrer. The volume ratios of oil $_{1}$ : oil ${ }_{2}$ phases were typically 20:80. The drug polymer mixture was then slowly introduced into 100 $\mathrm{ml}$ liquid paraffin previously emulsified with $1 \%$ Span 80, while stirring at $1500 \mathrm{rpm}$ held by the mechanical stirrer equipped with a three-blade propeller at room temperature. The whole system was stirred for 3 hrs. The prepared microspheres were kept undisturbed for few minutes to allow settling. The settled microspheres are then washed several times with n-hexane. After serial washing, microspheres were dried in an oven at room temperature not exceeding $25^{\circ} \mathrm{C}$.

Formulation design. Total six batches (each of $2 \mathrm{~g}$ ) were prepared, three using eudragit RSPO and the other three using eudragit RLPO. These two groups of microspheres were prepared in three degrees of drug loading (30, 50 and 70\%).

Table 1. Formulation protocol of different batches of microspheres.

\begin{tabular}{|c|c|c|c|}
\hline \multirow[b]{2}{*}{$\begin{array}{l}\text { Batch no. } \\
\text { (Batch size- } \\
2.0 \mathrm{~g} \text { ) }\end{array}$} & Drug & \multicolumn{2}{|c|}{ Polymer } \\
\hline & $\begin{array}{c}\text { Metformin } \\
\mathrm{HCl} \\
\text { (g) }\end{array}$ & $\begin{array}{l}\text { Eudragit } \\
\text { RLPO } \\
\text { (g) }\end{array}$ & $\begin{array}{c}\text { Eudragit } \\
\text { RSPO } \\
\text { (g) }\end{array}$ \\
\hline $\begin{array}{l}\text { A } 1 \\
\text { (30\% Drug + } \\
70 \% \text { Polymer) }\end{array}$ & 0.6 & 1.4 & 0 \\
\hline $\begin{array}{l}\text { A } 2 \\
\text { (50\% Drug + } \\
50 \% \text { Polymer) }\end{array}$ & 1.0 & 1.0 & 0 \\
\hline $\begin{array}{l}\text { A3 } \\
\text { (70\% Drug + } \\
30 \% \text { Polymer) }\end{array}$ & 1.4 & 0.6 & 0 \\
\hline $\begin{array}{l}\text { B1 } \\
\text { (30\%Drug + } \\
70 \% \text { Polymer) }\end{array}$ & 0.6 & 0 & 1.4 \\
\hline $\begin{array}{l}\text { B2 } \\
\text { (50\% Drug + } \\
50 \% \text { Polymer) }\end{array}$ & 1.0 & 0 & 1.0 \\
\hline $\begin{array}{l}\text { B3 } \\
\text { (70\% Drug + } \\
\text { 30\% Polymer) }\end{array}$ & 1.4 & 0 & 0.6 \\
\hline
\end{tabular}




\section{In vitro characterization of Metformin $\mathrm{HCl}$ microspheres:}

Determination of drug entrapment efficiency. $50 \mathrm{mg}$ of microspheres was taken in a mortar and triturated properly until fine powder was formed. 20 mg fine powder was taken in a screw cap test tube. 5 $\mathrm{ml}$ buffer was added to the powdered microsphere and was vortexed for 10 minutes. Then the solution was filtered and taken in a $100 \mathrm{ml}$ volumetric flask. The volume of the solution was adjusted to $100 \mathrm{ml}$ with the buffer solution. The absorbance was taken at $233 \mathrm{~nm}$. From the absorbance value, the amount of Metformin $\mathrm{HCl}$ entrapped was determined using standard curve. The drug entrapment efficiency was calculated by using the following equation-

Entrapment efficiency (\%) $=\frac{\text { Calculated conc. of drug }}{\text { Theoritical conc. of drug }} \times 100$

Particle size analysis. Particle size analysis was conducted in a laser diffracting particle size analyzer $\left(\right.$ Partica $\left.^{\circledR}\right)$. The microcapsules were dispersed in suitable solvent keeping the particle diameter unchanged.

In vitro dissolution study of microsphere containing Metformin HCl. In vitro dissolution study was performed in a paddle type (Type II) dissolution apparatus. Weighed amount of microspheres containing $100 \mathrm{mg}$ drug was taken from each batch of formulation for dissolution purpose. Phosphate buffer of $\mathrm{pH} 6.8$ was used as dissolution media, paddle speed was set at $100 \mathrm{rpm}$ and temperature was maintained fixed at $37^{\circ} \mathrm{C}$.

The dissolution process was carried out for 10 hours and $5 \mathrm{ml}$ dissolution sample from each dissolution media was withdrawn at a predetermined intervals of $1^{\text {st }}$ hour, $2^{\text {nd }}$ hour, $3^{\text {rd }}$ hour, $4^{\text {th }}$ hour, $5^{\text {th }}$ hour, $6^{\text {th }}$ hour, $7^{\text {th }}$ hour, $8^{\text {th }}$ hour, $9^{\text {th }}$ hour and $10^{\text {th }}$ hour. Each time $5 \mathrm{~m} 1$ of dissolution sample was compensated by fresh $5 \mathrm{~m} 1$ phosphate buffer $(\mathrm{pH}$ 6.8).

Dissolution samples withdrawn were filtered and taken in test tubes and analyzed spectrophotometrically in a UV-VIS spectrophotometer. The dissolution study for each batch was performed three times. The average of the percentage of release was calculated for each batch to find percentage of release.

Surface morphologic Study by scanning Electron Microscopy (SEM). Scanning electron microscopic study was employed to study the morphology and surface topography of the microspheres. The microspheres were mounted on the SEM sample stab (aluminum stabs) which were coated with a double-sided sticking tape, sealed and finally coated with gold $\left(200 \mathrm{~A}^{\circ}\right)$ under reduced pressure (0.001 torr) for 15 minutes using an ion sputtering device. The platinum coated samples were scanned using scanning electron microscope (S$3400 \mathrm{~N}$, Hitachi) under varying magnifications and photomicrographs of suitable magnifications were obtained. The microspheres were dried completely before examination.

\section{Compatibility Studies:}

Fourier transform infrared spectrophotometry (FTIR). The IR spectrum of the pure drug, pure polymers and optimized microsphere formulation were obtained to prove the chemical integrity and compatibility of the drug in the microsphere. The samples (about $5 \mathrm{mg}$ ) were powdered and intimately mixed with $250 \mathrm{mg}$ of pure dry powdered potassium bromide $(\mathrm{KBr})$ and the mixture was pressed into a disc using special mold and hydraulic press. The mixtures were taken in a diffuse reflectance sampler and spectrum was recorded by scanning in the wavelength region of 400 to $4000 \mathrm{~cm}^{-1}$ in a FTIR spectrophotometer.

Differential scanning calorimetry (DSC). Differential scanning calorimeter was used to measure the specific heat and enthalpies of transition. Samples, sealed in an aluminum pan in a nitrogen atmosphere went through a thermal transition, the power to the heater was adjusted to maintain the temperature and a signed proportional to the power difference was plotted on the second axis of the recorder known as thermogram. The area under the resulting curve is direct measure of the heat of transition. Thermograms were obtained by using a 
differential scanning calorimeter (Shimadzu DSC 60) at a flow rate of $20 \mathrm{ml} / \mathrm{min}$ and heating rate of $10^{\circ} \mathrm{C} /$ min over a temperature range of 30 to $300^{\circ} \mathrm{C}$.

\section{RESULTS AND DISCUSSION}

SEM analysis. SEM study revealed that the microspheres prepared from Eudragit RLPO and eudragit RSPO are generally spherical with few drug particle on the surface. The surfaces of the microspheres prepared by using Eudragit RSPO are smoother than the microspheres prepared using Eudragit RLPO. This may be one of the reasons of higher release retarding capability of Eudragit RSPO than Eudragit RLPO.

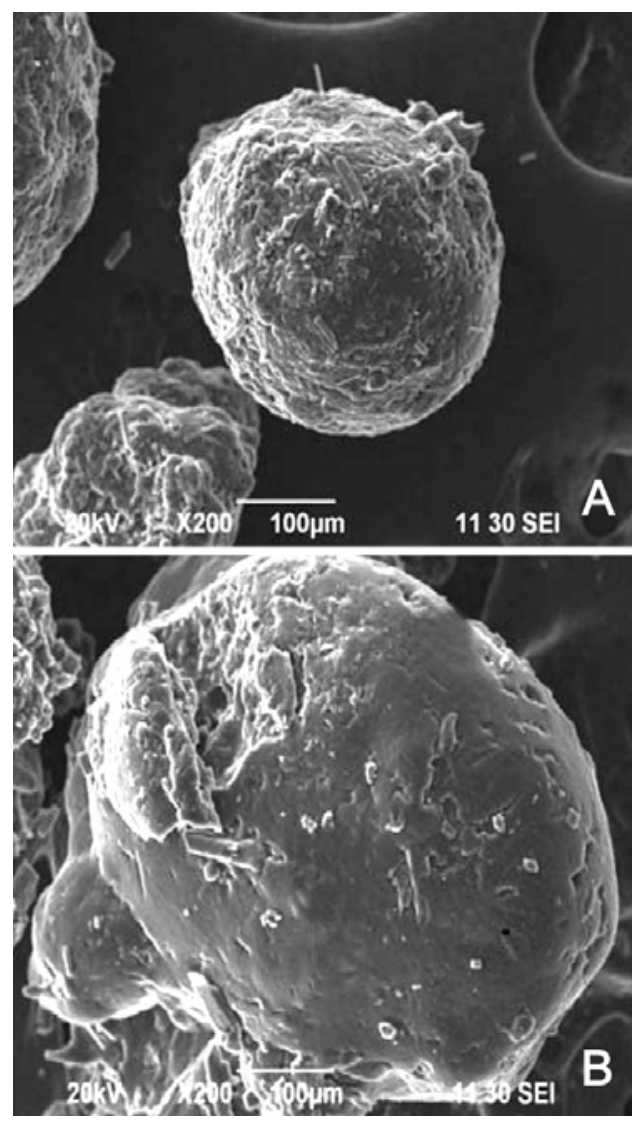

Figure 1. Scanning electron microscopic view of microspheres A. Batch-A2 (Microspheres prepared with Eudragit RLPO) B. Batch- B2 (Microspheres prepared with Eudragit RSPO).

Particle size analysis. Particle size of microspheres of all batches was within the acceptable size ranges in micrometer $(44.70 \mu \mathrm{m}-491.91 \mu \mathrm{m})$.
Table 2. Particle size distribution of all the batches of microspheres.

\begin{tabular}{ccc}
\hline Batch ID & $\begin{array}{c}\text { Mean size } \\
(\mu \mathrm{m})\end{array}$ & $\begin{array}{c}\text { Median size } \\
(\mu \mathrm{m})\end{array}$ \\
\hline A1 & 44.70 & 28.39 \\
A2 & 206.44 & 194.94 \\
A3 & 491.91 & 478.18 \\
B1 & 56.11 & 49.01 \\
B2 & 59.95 & 50.44 \\
B3 & 82.69 & 75.95 \\
\hline
\end{tabular}

Drug entrapment efficiency. Eudragit RSPO showed better incorporation efficiency than Eudragit RLPO. On the other hand, drug loading has direct effect on entrapment efficiency. Higher the drug loading higher is the entrapment efficiency.

Table 3. Entrapment efficiency (\%) of all the batches of microspheres.

\begin{tabular}{lccc}
\hline & $\begin{array}{c}\text { Sample } \\
\text { ID }\end{array}$ & $\begin{array}{c}\text { Drug } \\
\text { loading (\%) }\end{array}$ & $\begin{array}{c}\text { Entrapment } \\
\text { efficiency (\%) }\end{array}$ \\
\hline $\begin{array}{l}\text { Microspheres of } \\
\text { Eudragit RLPO }\end{array}$ & A1 & 30 & 77.09 \\
& A2 & 50 & 82.91 \\
$\begin{array}{l}\text { Microspheres of } \\
\text { Eudragit RSPO }\end{array}$ & B1 & 70 & 90.12 \\
& B2 & 50 & 88.55 \\
& B3 & 70 & 92.4 \\
\hline
\end{tabular}

In vitro dissolution study of microsphere containing Metformin $\mathrm{HCl}$ :

Effect of drug loading and polymeric ratio on release pattern of Metformin $\mathrm{HCl}$ microsphere. Microspheres of three different drug loading (30\%, 50\%, 70\%) using Eudragit RSPO and Eudragit RLPO were examined for dissolution pattern. The obtained data were subjected to various kinetic treatments for investigating their release pattern.

From the above release data it is clearly revealed that A1, A2 and A3 which were microspheres of Eudragit RLPO showed lower release retardation than the microspheres of Eudragit RSPO (B1, B2 and B3). After 10 hours almost all the drug of Eudragit RLPO microspheres were released; on the other hand for B1, B2 and B3 only 54.2, 67.3 and $69.78 \%$ drug were released. 


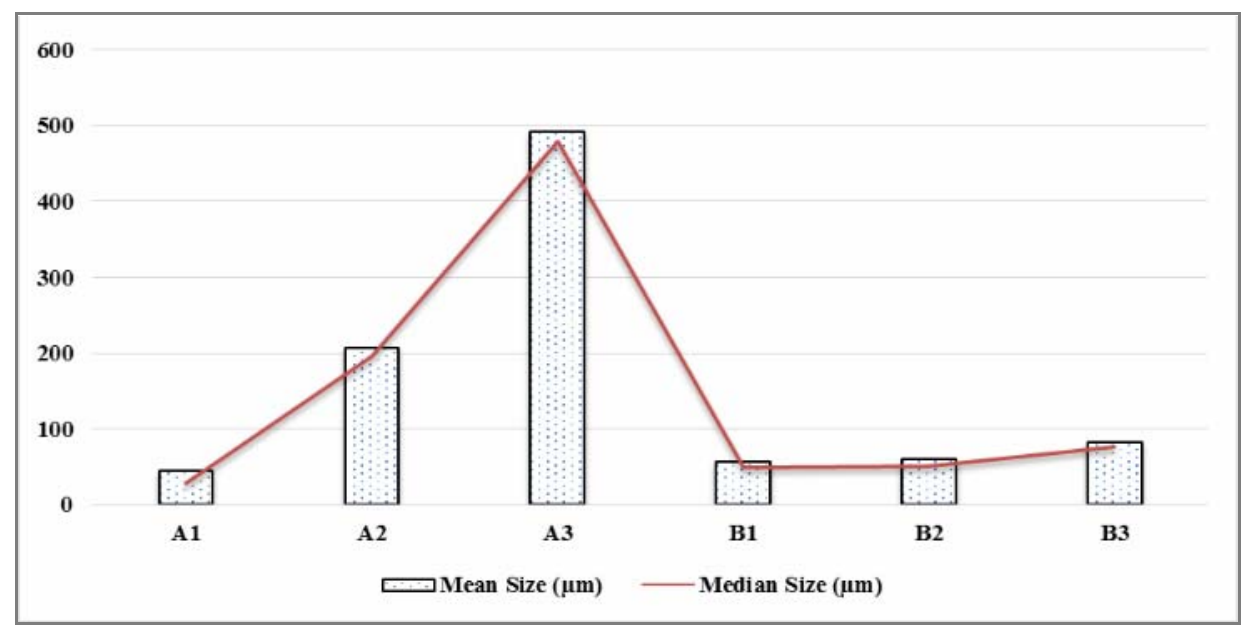

Figure 2. Bar diagram of particle size distribution.

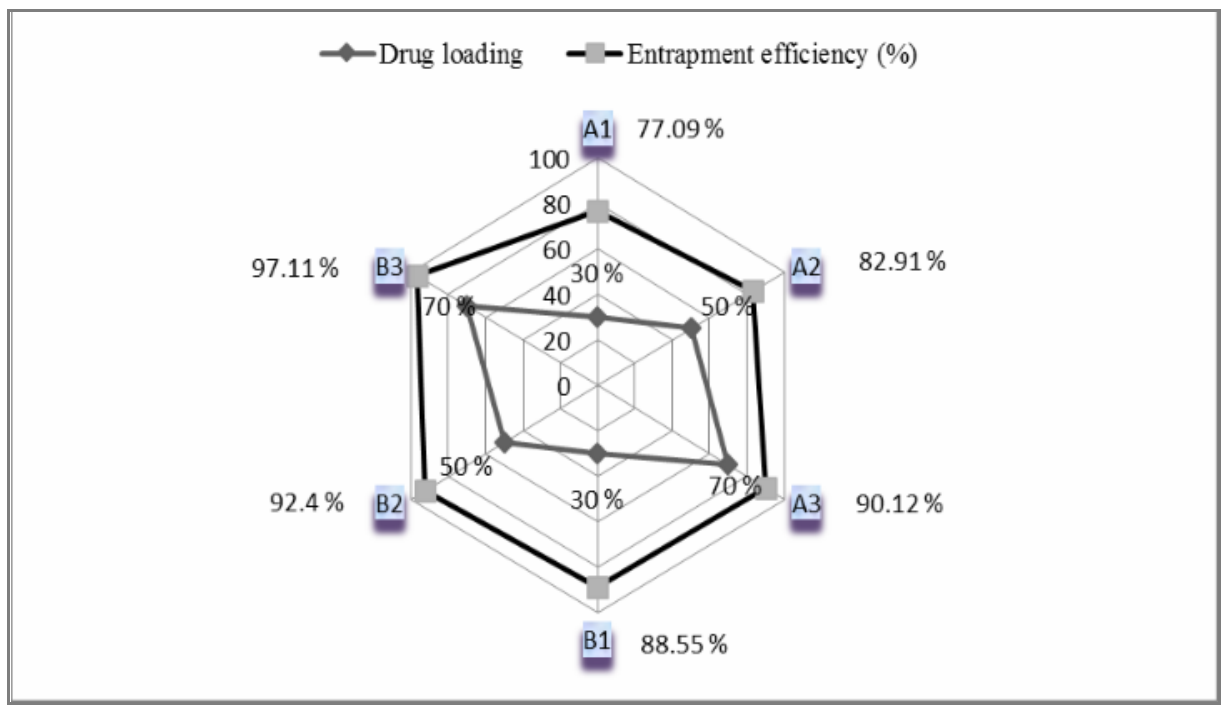

Figure 3. Effect of drug loading and polymeric type on entrapment efficiency.

Table 4. Zero order release profile of A1, A2, A3, B1, B2, and B3.

\begin{tabular}{|c|c|c|c|c|c|c|}
\hline \multirow{2}{*}{$\begin{array}{l}\text { Time } \\
\text { (hrs) }\end{array}$} & \multicolumn{6}{|c|}{ Cumulative $\%$ of drug released } \\
\hline & A1 & A2 & A3 & B1 & B2 & B3 \\
\hline 0 & 0 & 0 & 0 & 0 & 0 & 0 \\
\hline 1 & 50.6 & 61.6 & 67.5 & 12.3 & 17.5 & 20.98 \\
\hline 2 & 77.2 & 80.4 & 87.8 & 16.6 & 23.9 & 28.5 \\
\hline 3 & 85.3 & 89.8 & 92.5 & 21.5 & 29.7 & 37.4 \\
\hline 4 & 88.2 & 93.3 & 97.4 & 26.43 & 35.4 & 42.8 \\
\hline 5 & 91.38 & 95.5 & 99.5 & 32.2 & 40.7 & 46.4 \\
\hline 6 & 94.5 & 97.5 & 99.74 & 37.8 & 45.9 & 53.3 \\
\hline 7 & 97.4 & 99.3 & 99.89 & 43.9 & 51.5 & 57.66 \\
\hline 8 & 98.97 & 99.87 & 99.9 & 47.8 & 54.96 & 62.21 \\
\hline 9 & 99.38 & 99.92 & 99.91 & 50.4 & 61.5 & 65.45 \\
\hline 10 & 99.87 & 99.93 & 99.92 & 54.2 & 67.3 & 69.78 \\
\hline
\end{tabular}



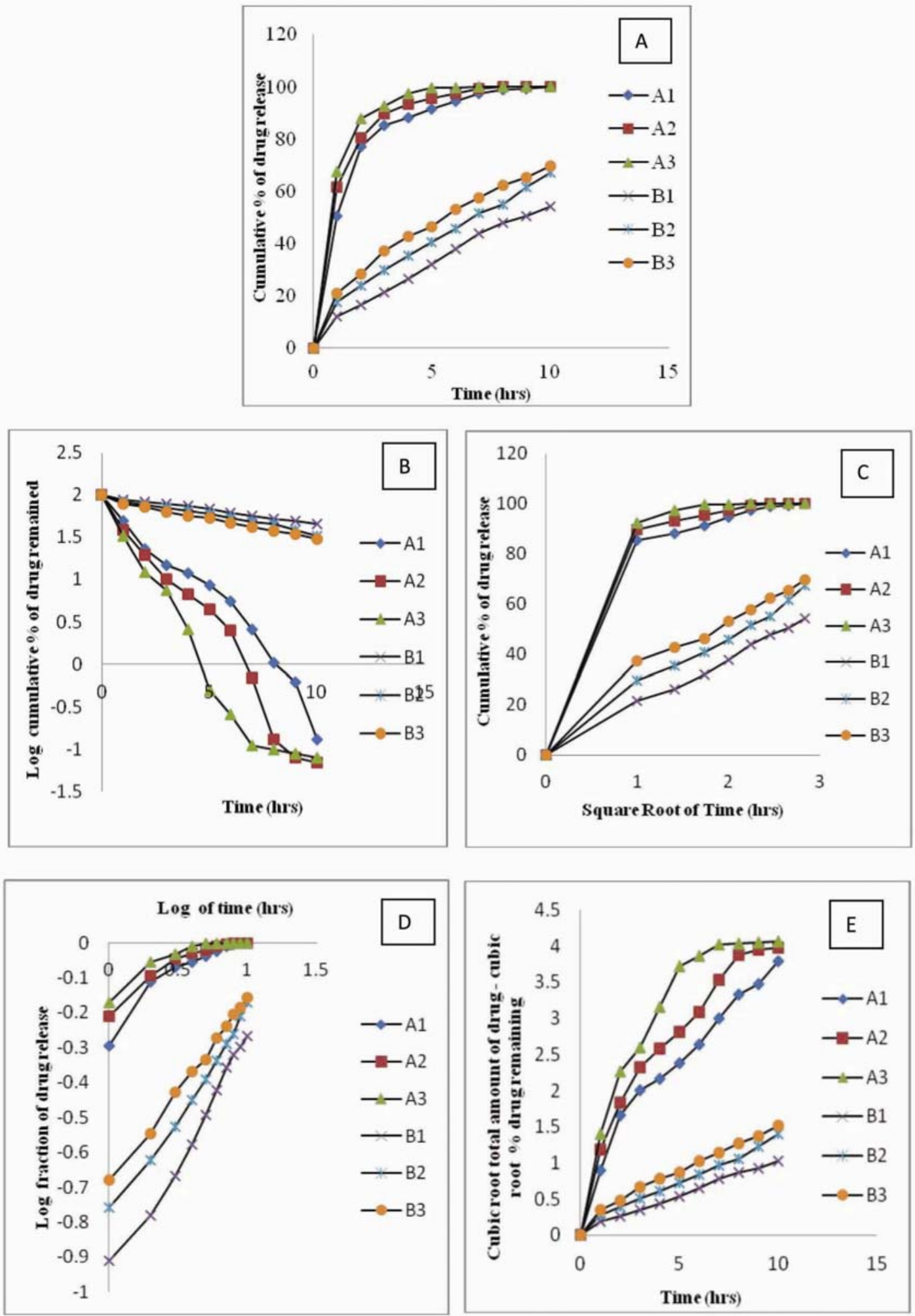

Figure 4. In vitro release kinetics of Metformin $\mathrm{HCl}$ microspheres; A. Zero order plot, B. First order plot, C. Higuchi plot, D. Korsmeyer plot, E. Hixson Crowell plot 
Table 5. Release rate constants and $\mathbf{R}^{2}$ values for different release kinetics of six formulations of Metformin $\mathrm{HCl}$ microspheres.

\begin{tabular}{ccccccccccccc}
\hline \multirow{2}{*}{ Formulations } & \multicolumn{2}{c}{ Zero order } & \multicolumn{2}{c}{ First order } & \multicolumn{2}{c}{ Higuchi } & \multicolumn{3}{c}{ Korsmeyer-Peppas } & \multicolumn{3}{c}{ Hixson- Crowell } \\
\cline { 2 - 13 } & $\mathrm{K}_{0}$ & $\mathrm{R}^{2}$ & $\mathrm{~K}_{1}$ & $\mathrm{R}^{2}$ & $\mathrm{~K}_{\mathrm{h}}$ & $\mathrm{R}^{2}$ & $\mathrm{n}$ & $\mathrm{K}_{\mathrm{kp}}$ & $\mathrm{R}^{2}$ & $\mathrm{~K}_{\mathrm{HC}}$ & $\mathrm{R}^{2}$ \\
\hline $\mathrm{A} 1$ & 8.146 & 0,714 & -0.57 & $\mathbf{0 . 9 7 6}$ & 31.14 & 0.901 & 0.379 & 0.479 & 0.941 & 0.349 & 0.952 \\
$\mathrm{~A} 2$ & 7.368 & 0.647 & -0.73 & $\mathbf{0 . 9 7 5}$ & 28.86 & 0.858 & 0.29 & 0.579 & 0.941 & 0.379 & 0.934 \\
$\mathrm{~A} 3$ & 6.579 & 0.564 & -0.77 & $\mathbf{0 . 9 7 1}$ & 26.5 & 0.791 & 0.22 & 0.67 & 0.93 & 0.383 & 0.853 \\
$\mathrm{~B} 1$ & 5.179 & $\mathbf{0 . 9 8 5}$ & -0.07 & $\mathbf{0 . 9 9 4}$ & 17.56 & 0.973 & 0.61 & 0.125 & $\mathbf{0 . 9 8 6}$ & 0.098 & $\mathbf{0 . 9 9 3}$ \\
$\mathrm{B} 2$ & 5.984 & $\mathbf{0 . 9 7 6}$ & -0.09 & $\mathbf{0 . 9 8 7}$ & 20.44 & $\mathbf{0 . 9 8 5}$ & 0.52 & 0.183 & $\mathbf{0 . 9 8 8}$ & 0.125 & $\mathbf{0 . 9 9}$ \\
$\mathrm{B} 3$ & 6.242 & 0.949 & -0.10 & $\mathbf{0 . 9 9 1}$ & 21.77 & $\mathbf{0 . 9 9 7}$ & 0.48 & 0.222 & $\mathbf{0 . 9 9 5}$ & 0.138 & $\mathbf{0 . 9 8 3}$ \\
\hline
\end{tabular}

Table 6. The best fitted model and mechanism of drug release from A1, A2, A3, B1, B2 and B3 batches of Metformin HCl microsphere. ${ }^{17-19}$

\begin{tabular}{llll}
\hline Formulation & Best fitted model & n value & Release mechanism \\
\hline A1 & First order & $\mathbf{0 . 3 7 9}$ & Fickian transport \\
A2 & First order & $\mathbf{0 . 2 9}$ & Fickian transport \\
A3 & First Order & $\mathbf{0 . 2 2}$ & Fickian transport \\
B1 & Zero order, First order, Korsmeyer-Peppas and & $\mathbf{0 . 6 1}$ & Anomalous / non- Fickian transport \\
& Hixson-Crowell & & \\
B2 & $\begin{array}{l}\text { Zero order, First order, Higuchi, Korsmeyer-Peppas } \\
\text { and Hixson-Crowell }\end{array}$ & $\mathbf{0 . 5 2}$ & Anomalous / non- Fickian transport \\
& $\begin{array}{l}\text { First order, Higuchi, Korsmeyer-Peppas and Hixson- } \\
\text { B3 }\end{array}$ & $\mathbf{0 . 4 8}$ & Anomalous / non- Fickian transport \\
& Crowell & & \\
\hline
\end{tabular}

Table 7. Successive fractional dissolution time of six formulations (A1, A2, A3, B1, B2 and B3) Metformin HCl microsphere.

\begin{tabular}{ccccc}
\hline Batch no. & $\begin{array}{c}\mathrm{T}_{25 \%} \\
(\mathrm{~min})\end{array}$ & $\begin{array}{c}\mathrm{T}_{50 \%} \\
(\mathrm{~min})\end{array}$ & $\begin{array}{c}\mathrm{T}_{80 \%} \\
(\mathrm{~min})\end{array}$ & $\begin{array}{c}\text { MDT } \\
(\mathrm{min})\end{array}$ \\
\hline A1 & 10.79058 & 67.1922 & 232.217 & 114.9921 \\
$\mathrm{~A} 2$ & 3.18306 & 35.92476 & 185.8234 & 90.17196 \\
A3 & 0.62526 & 15.4776 & 136.3651 & 68.05824 \\
B1 & 186.5672 & 580.1222 & 1251.973 & 684.147 \\
B2 & 109.3218 & 414.5822 & 1023.644 & 537.8663 \\
B3 & 76.72848 & 322.2606 & 852.7386 & 440.8225 \\
\hline
\end{tabular}

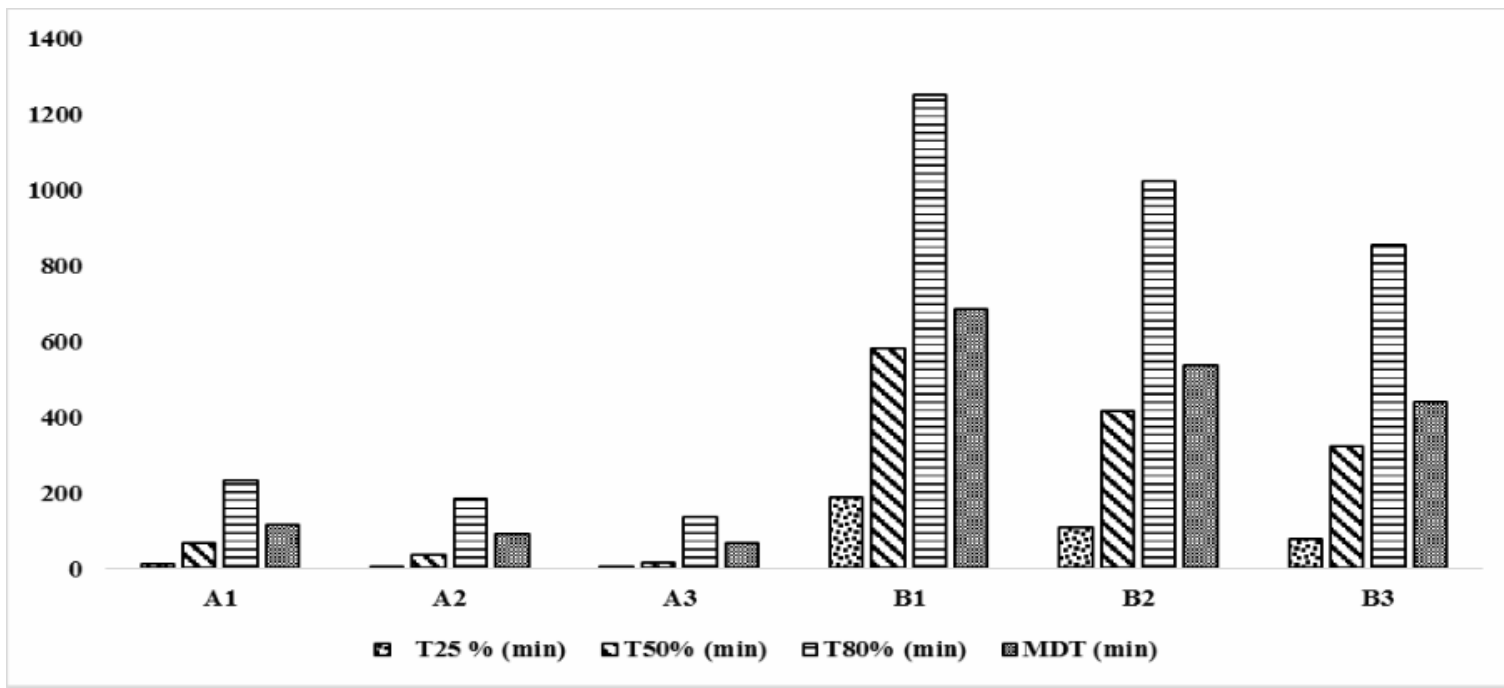

Figure 5. Bar diagram representing successive dissolution time of A1, A2, A3, B1, B2 and B3. 


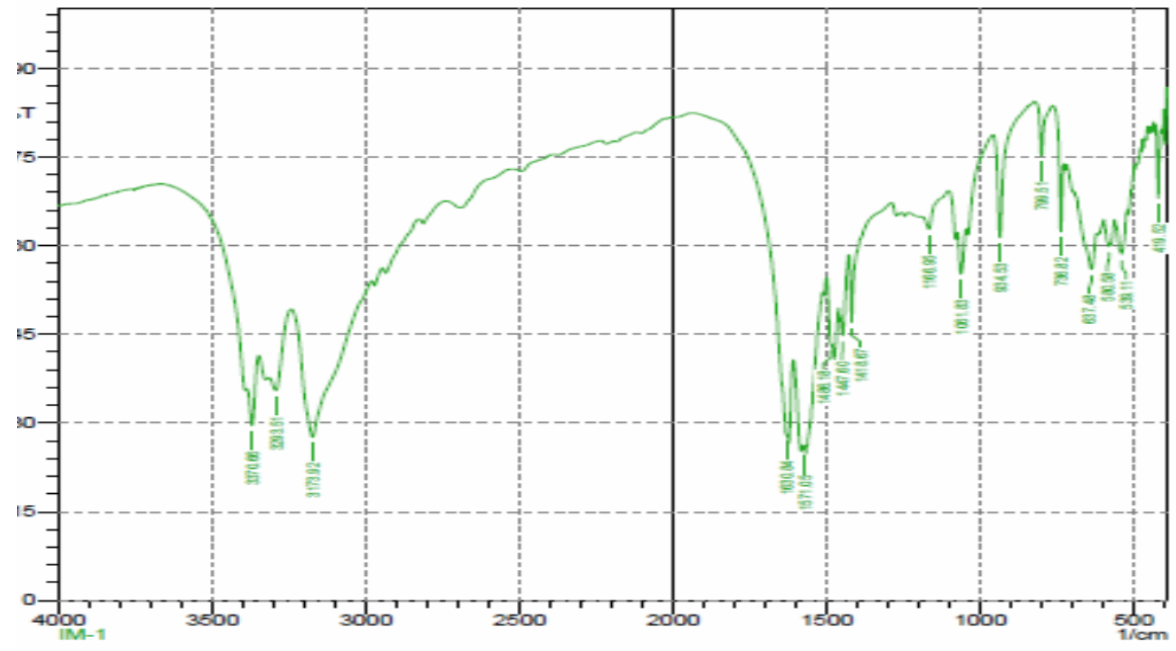

Figure 6. FTIR of pure metforfin $\mathrm{HCl}$.

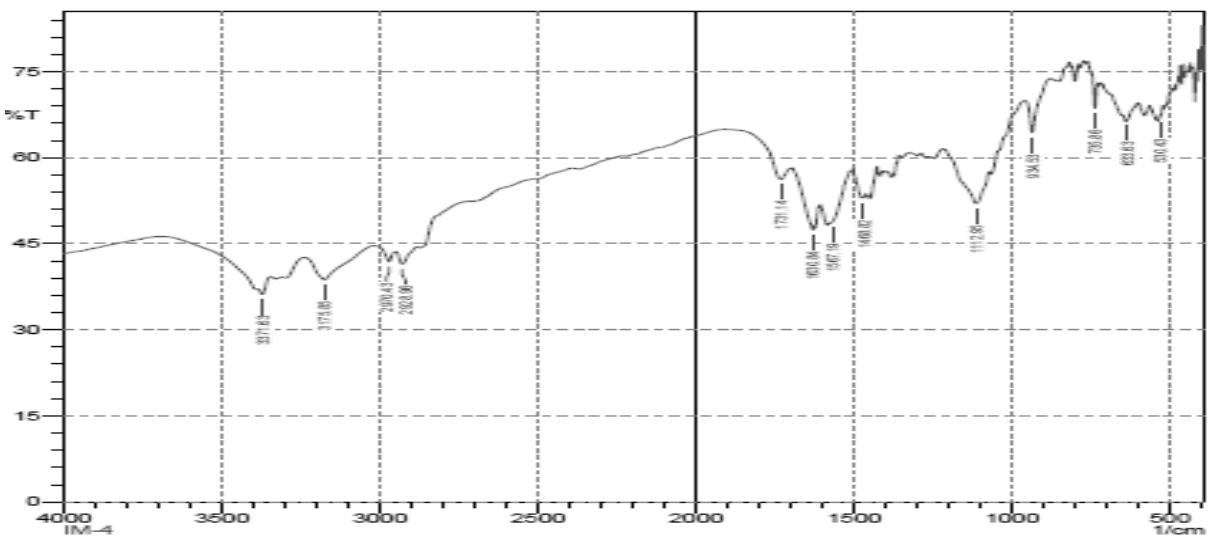

Figure 7. FTIR of A2 ( Metforfin HCl + Eudragit RLPO).

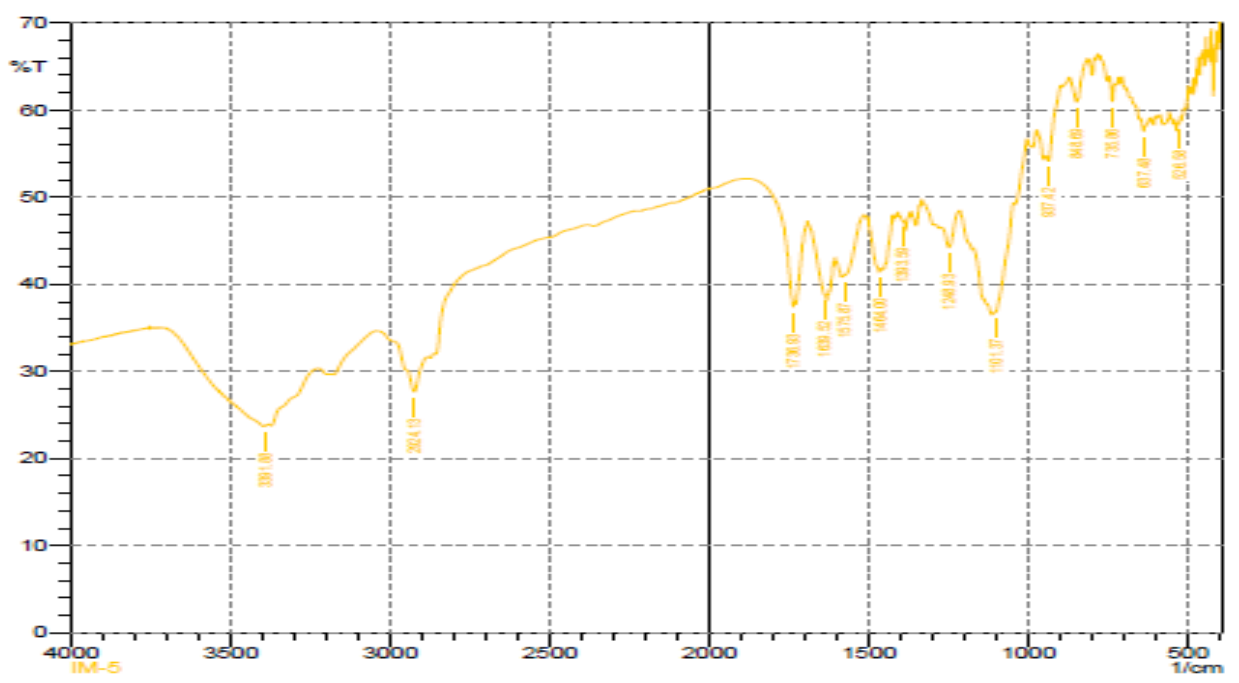

Figure 8. FTIR of B2 (Metformin $\mathrm{HCl}+$ Eudragit RSPO). 


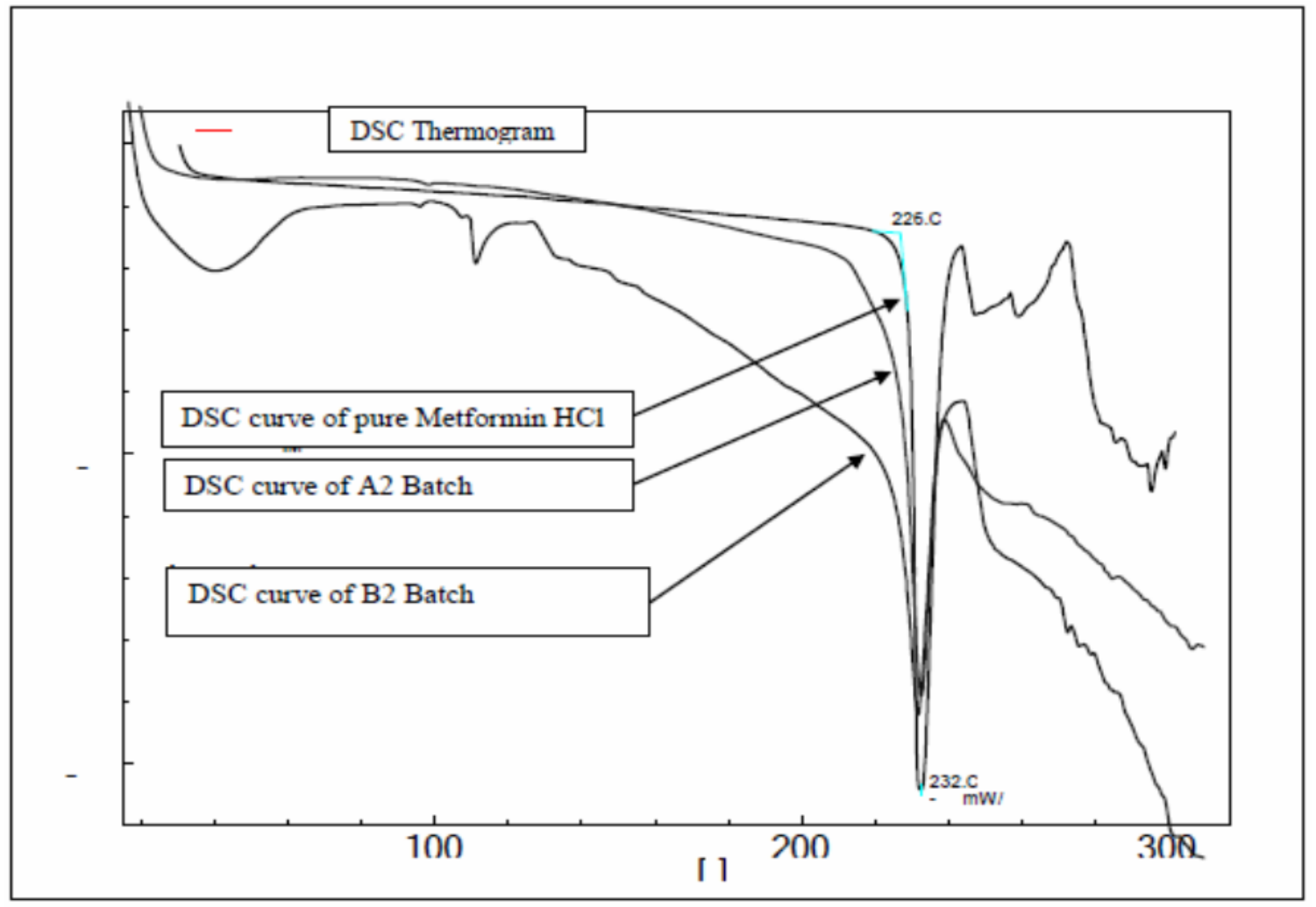

Figure 9. DSC thermogram of pure Metformin $\mathrm{HCl}$ and two batches of microspheres.

Successive fractional dissolution time. Successive fractional dissolution times of six formulations (A1, A2, A3, B1, B2 and B3) of Metformin $\mathrm{HCl}$ microsphere are discussed below. $\mathrm{T}_{25 \%}, \mathrm{~T}_{50 \%}, \mathrm{~T}_{80 \%}$ and MDT values were determined to characterize the drug release rate from the microspheres and the retaining efficiency of the polymers. A higher value of MDT indicates a higher drug retaining ability of the polymer and vice-versa.

\section{Drug compatibility studies:}

\section{Fourier Transform Infrared Spectroscopy (FTIR)}

Study. FTIR study was conducted for the following three samples:

1. Pure drug (Metformin $\mathrm{HCl}$ )

2. Sample A2 (Metformin $\mathrm{HCl}$ microsphere containing Eudragit RLPO)

3. Sample B2 (Metformin $\mathrm{HCl}$ microsphere containing Eudragit RSPO)
A lot of peaks are visible in this spectra but the most prominent peaks are-

1) Primary amine $\mathrm{N}-\mathrm{H}$ stretching at 3370.66 and bending at 1630.84

2) Imino compound N-H stretching at 3293.51and bending at 1571.05

3) Secondary amine N-H stretching at 3173.92 and bending at 1571.0

Figure 7 represents spectra of batch A2, a batch of microspheres prepared by using Eudragit RLPO. Secondary amine $\mathrm{N}-\mathrm{H}$ bending and stretching both are present here. $\mathrm{N}-\mathrm{H}$ stretching of imino compound and $\mathrm{N}-\mathrm{H}$ bending of primary amine are absent here, but most importantly $\mathrm{N}-\mathrm{H}$ bending of imino compound and $\mathrm{N}-\mathrm{H}$ stretching of primary amine are present at 1578.19 and 3371.63 , respectively, which are valid indication of the presence of these two groups.

Figure 8 represents spectra of batch B2, a batch prepared by using Eudragit RSPO. Secondary amine $\mathrm{N}-\mathrm{H}$ bending is present at 1575.87 though it`s 
stretching peak is absent. N-H stretching of imino compound and $\mathrm{N}-\mathrm{H}$ bending of primary amine are present here at 3291.88 and 1639.52, respectively, which are valid indication of the presence of these two groups, in other words indication of minimum interaction.

So, it can be concluded that there is minimum interaction between Metformin $\mathrm{HCl}$ and Eudragit RSPO and eudragit RLPO, in other word they are compatible to each other.

Differential Scanning Calorimetric (DSC) study. DSC studies were conducted for the following samples-

1) Metformin $\mathrm{HCl}$

2) Microspheres of batch $\mathrm{A} 2$ (Metformin $\mathrm{HCl}$ microspheres containing eudragit RLPO)

3) Microspheres of batch B2 (Metformin $\mathrm{HCl}$ microspheres containing eudragit RSPO)

No drastic changes occurred to the melting point of the microspheres in comparison with pure Metformin HCl. This means that there is no interaction in between drug and the polymers.

\section{CONCLUSION}

Microspheres of Metformin $\mathrm{HCl}$ were prepared successfully by emulsification-solvent evaporation technique; in fact it may be the premium technique for encapsulation of Metformin $\mathrm{HCl}$. The prepared microspheres are of good quality as all the microspheres possess spherical shape and the particle size of all the batches are within the acceptable range (1-1000 $\mu \mathrm{m})$.

Various variables like - drug loading and polymeric type all have direct effect on different characteristics of microsphere.

Microspheres prepared by using Eudragit RSPO showed highest entrapment efficiency and highest retardation of drug release when compared to the microspheres of Eudragit RLPO. Drug loading also influenced entrapment efficiency as well as release rate. The entrapment efficiency and drug release both increase with increase in drug loading.
The other parameters like surface morphology or particle size are also influenced by drug loading and polymeric properties. This however, reveals a newer approach to formulate Metformin $\mathrm{HCl}$ microspheres having optimized in vitro characteristics

\section{REFERENCES}

1. Bakan, J. A. Microencapsulation. 1986. In The Theory and Practice of Industrial Pharmacy, 3rd ed.; Lachman L., Lieberman, H.A., Kanig, J.L., Eds. Lea and Febiger: Philadelphia, PA, p. 412.

2. Hawlader, M.N.A., Uddin, M.S. and Khin, M.M. 2003 Microencapsulated PCM thermal-energy storage system. Appl. Energ. 74, 195-202.

3. Wieland-Berghausen, S., Schote, U., Frey, M. and Schmidt F. 2002. Comparison of microencapsulation techniques for the water-soluble drugs Nitenpyram and clomipramine HCl. $J$. Control. Rel. 85, 35-43.

4. Yamuda T., Onishi, H. and Machida Y. 2001. Sustained release ketoprofen microparticles with ethyl cellulose and carboxymethyl ethyl cellulose. J. Control. Rel.75, 271-282.

5. Bolourtchian, N., Karimi, K. and Aboofazeli R. 2005. Preparation and characterization of ibuprofen microspheres. J. Microencapsulation, 22, 529-538.

6. Clinical Guidelines Task Force, International Diabetes Federation (2005). "Glucose control: oral therapy". In: Global Guideline for Type 2 Diabetes. Brussels: International Diabetes Federation, 35-8. Retrieved on November 6, 2007.

7. National Collaborating Centre for Chronic Conditions. Type 2 diabetes: National clinical guideline for management in primary and secondary care (update). London: Royal College of Physicians; 2008. ISBN 978-1-86016-333-3. p. 86.

8. American Diabetes Association. Standards of medical care in diabetes. 2009. Diabetes Care. 2009; 32 Suppl 1:S13-61. Doi: 10.2337/dc09-S013. PMID 19118286.

9. Lord, J.M., Flight, I.H.K. and Norman, R.J. 2003. Metformin in polycystic ovary syndrome: systematic review and metaanalysis. BMJ. 327, 951-3. doi:10.1136/bmj.327.7421.951. PMID 14576245. PMC 259161.

10. Kidson, W. 1998. Polycystic ovary syndrome: a new direction in treatment. Med. J. Aust. 169, 537-40. PMID 9861912.

11. Bolen, S., Feldman, L. and Vassy, J. 2007. Systematic review: comparative effectiveness and safety of oral medications for type 2 diabetes mellitus. Ann. Inter. n. Med. 147, 386-99. PMID 17638715.

12. Haznedar, S. and Dortunç B. 2004. Preparation and in vitro evaluation of Eudragit microspheres containing acetazolamide. Int. J. Pharm. 269, 131-140. 
13. Horoz, B.B., Kiliic, M., Arslan, N. and Baykara Y.T. 2004. Effect of different dispersing agents on the characteristics of Eudragit microspheres prepared by a solvent evaporation method. J. Microencapsulation. 21, 191-202.

14. Carli. F., Capone, G. and Colombo, I. 1984. Surface and transport properties of acrylic polymers influencing drug release from porous matrices. Int. J. Pharm. 21, 317-329.

15. Nath, B., Nath, L.K., Mazumdar, B., Sharma, N. and Sarkar, M. 2009. Design and development of Metformin HCl floating microcapsules using two polymers of different permeability characteristics. Intl. J. Pharm. Sci. Nanotechnology 2, $627-$ 637.
16. Peppas, N.A. 1985. Analysis of Fickain and non-Fickian drug release from polymers. Pharm. Acta. Helv. 60, 110-112.

17. Korsmeyer, R.W., Gurny, R., Doelker, E.M., Buri, P. and Peppas, N.A. 1983. Mechanism of solute release from porous hydrophilic polymers. Intl. J. Pharmaeutics 15, 25-35.

18. Higuchi, T. 1963. Mechanism of sustained action medication, theoretical analysis of rate of release of solid drugs dispersed in solid matrices. J. Pharm. Sci. 52, 1145-1149. 